\title{
MOLÉSTIA DE CHAGAS AGUDA EXPERIMENTAL: PARASITISMO DO HIPOTÁLAMO
}

\author{
EDYMAR JARDIM *
}

Vários trabalhos realizados no sentido de testar algumas funções orgânicas em chagásicos crônicos, vieram evidenciar a ocorrência de certas disfunçōes que dependem de uma agressão ao sistema nervoso central ou periférico. Assim, Lomônaco ${ }^{15}$ assinalou grande labilidade da homeostase tireoidiana, em dosagens de iôdo ligado a proteina; Reis ${ }^{17}$, observando as curvas glicêmicas, notou grandes discrepâncias nos resultados, quando comparados aos de grupo contrôle; Jardim ${ }^{10}$, verificando a sudação provocada por estímulo térmico, notou considerável diminuição relativamente aos individuos não chagásicos; Vieira, Mazzoncini e Lomônaco ${ }^{19}$ constataram hiperpotassemia num grande grupo de chagásicos crônicos, com vários tipos de alterações orgânicas.

Tais observações de caráter funcional não tiveram, até o momento, fundamentos de natureza anatômica para justificá-las, sendo esta uma das razões para a presente pesquisa. Mediante estudo histopatológico do hipotálamo na fase aguda da doença de Chagas no rato, procuramos verificar as eventuais alteraçōes, tentando extrapolá-las para a patologia hı:mana.

\section{MATERIAL E METODOS}

Nosso material consta de 16 ratos de linhagem Wistar, procedentes do biotério da Faculdade de Medicina de Ribeirāo Prêto: 11 foram inoculados com a cepa $\mathrm{Y}$ do T. cruzi; os $\mathbf{5}$ animais restantes constituiram o grupo contrôle.

A inoculaçāo foi feita por via intraperitonial, usando-se $0,15 \mathrm{ml}$ de sangue citratado obtido por punção cardiaca de outros ratos inoculados para a manutenção da cepa. O número de tripanosomas inoculados foi, em média, de 15 a 20 por campo de $400 \times$, verificado no momento da inoculação mediante exame de gôta espêssa de sangue colocada entre lâmina e laminula.

A parasitemia dos animais inoculados foi verificada a partir do primeiro dia da inoculação, em gôta espêssa de sangue colhido da ponta da cauda do animal, colocada entre lâmina e laminula, e os tripanosomas foram contados em campos de $400 \times$.

Para o estudo histopatológico, foram aproveitados exclusivamente aqueles animais cuja sintomatologia clínica final e morte foram presenciadas, evitando-se, desta forma, que pela demora da fixação do material, pudesse ocorrer autólise do sistema nervoso central. Os animais do grupo contrôle foram sacrificados no 20.'

Trabalho do Departamento de Neuropsiquiatria e Psicologia Médica da Faculdade de Medicina de Ribeirâo Prêto da Universidade de São Paulo: * Docente. 
dia da experimentação, por degola, com a finalidade de obter morte rápida e melhor fixação do material. O encéfalo dos animais foi incluído em parafina e cortado em série na espessura de oito micra. o sentido dos cortes foi coronal, iniciando-se sempre pelo polo frontal. Na fixaçāo do material foi utílizado o formol a $10 \%$. Para a coloração usamos a hematoxilina-eosina.

Para o estudo anatômico, tomamos como referência o trabalho de J. de Groot*, que apresenta secçōes coronais do encéfalo de rato para estudos de estereotaxia, o qual se mostrou bastante satisfatório para localização dos vários núcleos hipotalãmicos. Para melhor estudo das alteraçōes causadas pela parasitose, subdividimos o hipotálamo nas suas porçōes anterior, média e posterior, segundo a maneira clássica e estudamos três núcleos de cada regiāo. O hipotálamo anterior fica limitado rostralmente pela borda anterior do quiasma óptico e, caudalmente, pela borda posterior do quiasma; nêste compartimento verificamos o parasitismo nos núcleos supraóptico, paraventricular e da área hipotalâmica anterior. O hipotálamo médio tem como limite rostral a borda posterior do quiasma óptico e, como limite caudal, o desaparecimento dos núcleos arqueados; nesta região estudamos os núcleos dor'somediais, ventromediais e os arqueados. O hipotálamo posterior é identificado anteriormente pela presença dos núcleos pré-mamilares e, caudalmente, pela presença dos núcleos mamilares laterais; aqui estudamos os núcleos pré-mamilares dorsais, mamilares medais e mamilares laterais.

Pretendendo complementar as observaçōes histopatológicas nas várias regiōes hipotalâmicas, além da observação do parasitismo, fizemos contagens neuronais em cada um dos niveis considerados. Assim, no hipotálamo anterior contamos neurônios no núcleo supraóptico; no hipotálamo médio, no núcleo ventromeđial; no hipotálamo posterior, no núcleo mamilar lateral. Utilizamos uma ocular microscópica dotada de um retículo de $5 \mathrm{~mm}$ de lado, e contamos tôdas as células contidas no interior do retículo, mesmo aquelas que apresentavam alteraçōes estruturais evidentes. Foram contados neurônios em 20 cortes diferentes de cada nucleo, em cada animal, obtendo-se, assim, médias parciais e finais para cada núcleo.

Para a análise estatística dêsses resultados foi utilizado o método não paramétrico preconizado por White ${ }^{20}$, comparando-se as médias pela estatística de ordem.

Os animais do grupo contrôle são representados no texto pela letra $\mathrm{C}$ e, os inoculados, por $\mathrm{R}$.

\section{R E S U L T A D O S}

No estudo histopatológico observamos que, dos 11 animais inoculados, 10 apresentaram parasitismo encefálico, correspondendo a $90,9 \%$; apenas o animal R-22 não apresentou parasitas na região encefálica $(9,1 \%)$.

Dentre os 10 animais com parasitismo encefálico, em 7 encontramos formas de leishmania do $T$. cruzi, na regiāo do hipotálamo, perfazendo a elevada percentagém de $70 \%$ de agressão parasitária a esta zona cerebral (Tabela 1 ).

A distribuição do parasitismo em relação aos níveis hipotalâmicos anterior, médio e posterior, mostrou predominio das porçōes anterior e média, o que poderá ser atribuido a uma irrigação sangüinea mais pronunciada destas regiões (Tabela 2). Sete animais tinham parasitas na porção anterior, cinco nas porções anterior e média, e dois nas porçōes anterior, média e posterior.

O parasitismo quanto aos núcleos hipotalâmicos estudados separadamente, mostrou-se predominante na área hipotalâmica anterior, seguindo-se em ordem de freqüência, os núcleos suprápticos, paraventriculares, dorsomediais e ventromediais. Os núcleos pré-mamilares, mamilares mediais, mamilares laterais e arqueados, foram as localizações com menor evidência de parasitismo. Nos núcleos arqueados notamos a presença de parasitas em apenas um animal (R-14). o qual, dentre todos os animais estudados, foi aquêle que apresentou parasitismo mais acentuado em tôdas as regiōes examinadas (Tabela 3 ). 


\begin{tabular}{ccc}
\hline $\begin{array}{c}\text { Animais com parasitas } \\
\text { no hipotálamo }\end{array}$ & $\begin{array}{c}\text { Animais com parasitas } \\
\text { no encéfalo e nāo no } \\
\text { hipotálamo }\end{array}$ & $\begin{array}{c}\text { Animal sem parasitas } \\
\text { no encéfalo }\end{array}$ \\
\hline $\mathrm{R}-1$ & $\mathrm{R}-8$ & $\mathrm{R}-22$ \\
$\mathrm{R}-4$ & $\mathrm{R}-20$ & \\
$\mathrm{R}-5$ & $\mathrm{R}-24$ & \\
$\mathrm{R}-9$ & & \\
$\mathrm{R}-10$ & & \\
$\mathrm{R}-12$ & & \\
$\mathrm{R}-14$ & & \\
\hline
\end{tabular}

Tabela 1 - Distribuiça do parasitismo em relação ao encéfalo e à regiño hipotalámica.

\begin{tabular}{|c|c|c|}
\hline Região anterior & Regiāo média & Região posterior \\
\hline $\mathrm{R}-1$ & $R-4$ & $R-10$ \\
\hline R- 4 & $R-5$ & $\mathrm{R}-14$ \\
\hline R- 5 & R- 9 & \\
\hline R- 9 & $\mathrm{R}-10$ & \\
\hline$R-10$ & $\mathrm{R}-14$ & \\
\hline \multicolumn{3}{|l|}{$\mathrm{R}-12$} \\
\hline $\mathrm{R}-14$ & & \\
\hline
\end{tabular}

Tabela 2 - Distribuição do parasitismo em relaç̃o às regiões hipotalâmicas.

\begin{tabular}{|c|c|c|c|c|c|c|c|c|c|}
\hline Animal & AHA & So & PV & DM & VM & AR & $\mathrm{PM}$ & MM & ML \\
\hline$R-1$ & + & + & + & & & & & & \\
\hline$R-4$ & + & & + & + & + & & & & \\
\hline$R-5$ & + & + & & + & + & & & & \\
\hline R- 9 & + & & + & + & + & & & & \\
\hline $\mathrm{R}-10$ & + & + & + & + & + & & & & \\
\hline $\mathrm{R}-12$ & & + & & & & & + & + & + \\
\hline$R-14$ & + & + & + & + & + & + & + & + & + \\
\hline
\end{tabular}

Tabela 3 - Distribuiçāo do parasitismo em relaç̃ó aos núcleos hipotalamicos. $A H A=A r e a$ hipotalámica anterior; $S O=n u ̈ c l e o$ supraóptico; $P V=$ núcleo paraventricular; $D M=$ nucleo dorsomedial; $V M=$ núcleo ventromedial; $A R=$ núcleo arqueado; $P M=$ núcleo pré-mamilar dorsal; $M M=$ núcleo mamilar medial; $M L=$ núcleo mamilar lateral. 
O comprometimento do hipotálamo, como vimos de constatar, não é encontrado em todos os casos, pois os animais R-8, R-20 e R-24 apesar de possuirem parasitas no encéfalo não os apresentaram especlficamente naquela região.

As formas em leishmania encontradas mostraram-se esparsas ou agrupadas em pseudocistos, sendo muito mais freqüente a última eventualidade.

Apesar das preparações histológicas não representarem a técnica de eleição para a observação de alterações celulares, pois tal elemento não é o objetivo dêste trabalho, foi possivel verificar, com freqüência, áreas de evidente pobreza neuronal, neurônios e glia astrocitária com alterações isquêmicas, tigrólise central, picnose nuclear, tumefação da oligodendroglia, proliferação do endotélio dos pequenos vasos e infiltrados inflamatórios perivasculares moderados.

A comparação das médias neuronais encontradas nos grupos contrôle e chagásico, utilizando-se o método não paramétrico de estatística de ordem (White "), veio mostrar que a diferenca entre os grupos, foi estatisticamente significante ao nivel de $5 \%$ para os núcleos suprábticos e ventromediais, não acontecendo o mesmo para os núcleos mamilares laterais. A redução do número de neurônios ao nivel dos núcleos suprápticos e ventromediais nos animais chagásicos é concordante com a maior intensidade do parasitismo encontrado no hipotálamo anterior e médio. Ao nivel da região hipotalâmica posterior, representada nas contagens, pelos núcleos mamilares laterais, a comparação das médias neuronais não se mostrou estatisticamente significante, concordando dessa maneira com o discreto parasitismo verificado nessa região (Tabelas 4 e 5 ).

\begin{tabular}{cccc}
\hline Animal & $\begin{array}{c}\text { Núcleo } \\
\text { Supraóptico }\end{array}$ & $\begin{array}{c}\text { Núcleo } \\
\text { ventromedial }\end{array}$ & $\begin{array}{c}\text { Núcleo } \\
\text { mamilar lateral }\end{array}$ \\
\hline C-1 & $111^{*}$ & 126 & 88 \\
C-2 & 133 & 131 & 96 \\
C-3 & 141 & 142 & 106 \\
C-4 & 103 & 112 & 102 \\
C-5 & 118 & 139 & 99 \\
\hline Médias & 121,2 & 130,0 & 98,2 \\
\hline
\end{tabular}

'labela 4 - Contagem de neurônios nos animais contrôle. * número correspondente à média de neurônios contados em 20 cortes.

\begin{tabular}{cccc}
\hline Animal & $\begin{array}{c}\text { Núcleo } \\
\text { supráptico }\end{array}$ & $\begin{array}{c}\text { Núcleo } \\
\text { ventromedial }\end{array}$ & $\begin{array}{c}\text { Núcleo } \\
\text { mamilar lateral }\end{array}$ \\
\hline R- 1 & $108^{*}$ & 82 & 94 \\
R- 4 & 92 & 105 & 98 \\
R- 5 & 95 & 89 & 98 \\
R- 9 & 76 & 114 & 86 \\
R-10 & 90 & 85 & 85 \\
R-12 & 107 & 90 & 102 \\
R-14 & 87 & 79 & 96 \\
\hline Médias & 93,6 & 92,0 & 94,1 \\
\hline
\end{tabular}

'Tabela 5 - Contagem de neurônios nos animais chagásicos: * número correspondente à média de neurónios contados em 20 cortes. 


\section{COM E N T A R I O S}

Segundo Köberle e Alcântara ${ }^{12}$, as alterações neuronais são subseqüentes ao parasitismo tecidual pelo $T$. cruzi, representado pelas formas em leismania. As lesões neuronais seriam, na concepção dêsses autores, decorrentes de uma substância tóxica liberada pela desintegração dos parasitas. Esta circunstância, suspeitada por Chagas ${ }^{5}$ e por Crowell ${ }^{7}$, foi também admitida mais recentemente por Torres ${ }^{18}$ e Alvarenga ${ }^{1}$. Êste último autor, estudando camundongos inoculados com $T$. cruzi, sugeriu a existência de uma substância neurotóxica liberada ao nível dos tecidos parasitados, e "capaz de lesar qualquer tipo de tecido".

Entretanto, até o momento, não foi possivel isolar um princípio neurotóxico de origem parasitária ou tecidual, elemento que, na opinião de Köberle ${ }^{13}$ não é de relêvo, pois "o fato fundamental reside na destruição neuronal", sendo a causa desta destruição fator secundário.

Prates Campos ${ }^{16}$ em pesquisa de avaliação da síntese protêica das células de Purkinje do cerebelo de ratos inoculados com T. cruzi, mediante administração de DL-leucina, 4-5 $\mathrm{T}$ (leucina $\mathrm{H}_{3}$ ) e utilizando a técnica radioautográfica, concluiu que, na fase aguda da doença de Chagas, existe uma disfunção metabólica da célula nervosa, traduzida por uma diminuição da sintese protêica. Esta disfunção ocorre paralelamente ao aumento do parasitismo local das células gliais, na ausência de infiltração inflamatória local e de parasitismo direto do neurônio. A lesão das células gliais parasitadas repercutiria sôbre o metabolismo do neurônio assistido por essa glia.

Admite-se que tôdas as funçōes do organismo sejam influenciadas, direta ou indiretamente, pelo hipotálamo sendo que, ao nível dessa estrutura, não existe uma separação nitida entre funções neurovegetativas e somáticas, como acontece perifèricamente. Da estimulação de determinada região podem resultar manifestações de um tipo ou de outro, como demonstraram Hess ${ }^{9}$ e outros pesquisadores. O papel do hipotálamo é de grande importância, pois o organismo tem necessidade de manter dentro de limites bastante precisos, a composição de seus líquidos circulantes, no interior dos quais vivem as células. Na regulação dêste meio adequado à vida celular, que irá condicionar o bom funcionamento dos vários sistemas, entra em jôgo um grande número de fatôres de ordem nervosa e humoral, que são, na sua maior parte, influenciados por centros nervosos situados na região hipotalâmica. Dai, poderemos concluir que lesões neuronais nesta região poderão levar à perturbações do funcionamento dos sistemas dela dependentes. Para exemplicar, diremos que já se demonstrou que o hipotálamo pode modificar diretamente, por uma ação primária neurogênica, a ingestão de sódio (Antunes-Rodrigues ${ }^{3},{ }^{4}$ ); Anderson e col. ${ }^{2}$ demonstraram que lesões mesencefálicas em cães traziam graves alteraçōes endócrinas e metabólicas, entre as quais a perda de sódio e potássio. Por outro lado, os principais elementos destinados à regulação da temperatura corporal, estão também localizados na região hipotalâmica.

Podemos inferior do expôsto que as alterações funcionais relativas à homecstase tireoidiana e glicídica, à sudação e à regulação da potassemia, sejam 
decorrentes de uma agressão ao hipotálamo na fase aguda da doença, pois, como afirmou Köberle ${ }^{11}$, o destino do chagásico decide-se na fase aguda. As alterações encontradas representariam seqüelas desta fase "que consistiriam numa redução numérica mais ou menos acentuada dos neurônios, decorrente de uma destruição neuronal em tôrno dos pseudocistos rôtos" (Köberle ${ }^{14}$ ).

Para Chagas ${ }^{5}$, agressão ao sistema nervoso central poderia fazer-se também em época muito posterior à fase aguda da infecção, quando ausentes todos os sinais do período agudo", num surto de reativação da doença. O teor das aiteraçōes funcionais dependeria em última análise, da intensidade e da localização de agressão, levando-se em conta, todavia, que "a substância nervosa não constitui de modo constante, ou pelo menos com a constância do miocárdio, séde da multiplicaçāo do tripanosoma" (Chagas ${ }^{6}$ ).

Nossa experiência com os exames neurológicos de numerosos chagásicos crônicos apresentando ou não, patologias circulatórias ou digestivas, mostra que as alterações semiológicas mais encontradiças são as hipo ou arreflexias tendinosas profundas; mais raramente são observados comprometimento de nervos cranianos e síndromes de cordão posterior, síndromes cerebelares, oligofrenias, distúrbios da motricidade voluntária. Êsses casos são rotulados como de origem chagásica, quando não se consegue evidenciar patologias de outra natureza, mòrmente quando resulta positiva a reação de Machado Guerreiro.

Entretanto, a maior parte dos pacientes chagásicos crônicos nada apresenta ao exame neurológico realizado nos moldes da semiologia clássica. Nestes casos, a aplicação de provas funcionais como a do iôdo ligado à proteina, das curvas de tolerância à glicose, da sudação por estímulo térmico e da dosagem do potássio sanguíneo, permitiriam evidenciar comprometimento do sistema nervoso central, que não poderia ser demonstrado pela semiologia tradicional. Tais dados sugerem que novas avaliaçōes devam ser feitas em relação a outros tipos de testes paraclínicos em pacientes chagásicos crônicos, pois sòmente assim poderemos encontrar, gradativamente, novos subsidios para o diagnóstico clínico das formas nervosas crônicas da moléstia de Chagas.

\section{R E S U M O}

O autor procurou relações entre alterações funcionais atribuidas ao hipotálamo e lesões orgânicas do mesmo, na vigência da moléstia de Chagas. Usou em seu trabalho ratos inoculados com $T$. cruzi por via intraperitonial. Realizou estudo histopatológico e quantitativo neuronal das várias regiões hipotalâmicas, em cortes seriados corados com a hematoxilina-eosina. Encontrou considerável percentagem de parasitismo hipotalâmico $(70 \%)$, sendo que a região anterior é mais parasitada que a média ou a posterior. A destruição neuronal foi também mais evidente na região anterior. Sugere que as alterações do metabolismo glicídico, tireoidiano, da sudação e da potassemia, devam ser consideradas como seqüelas destas lesōes. 
S U M M A R Y

Experimental acute Chagas disease in the rat: parasitism of hypothalamus

This work search relations between functional impairments imputed to hypothalamus and organic lesions in Chagas' disease. The author used rats with $T$. cruzi inoculation by intraperitonial way. Histopathologic and quantitative neuronal studies were done by serial sections of hypothalamus. It was demonstrated that the anterior hypothalamic region is more parasited than others, with greater neuronal destruction also. The author suggests that impairments of glycidic and thyroidian metabolism, of sweating and potassium blood level, must be considered as sequels of these lesions.

\section{R E F E R E N I A S}

1. Alvarenga, R. J. - Histopatologia da fase aguda da moléstia de Chagas em camundongos. An. Congr. Intern. Mol. Chagas, Rio de Janeiro, 1959.

2. ANDERSON, E.; BATES, R. W.; HAWTORNE, E.; HAYMAKER, W.; KNOWLTON, R.; RIOCH, D.Mc K.; SPENCE, W. T. \& WILSON, H. - The effects of midbrain and spinal cord transection on endocrine and metabolic functions with postulation of hypothalamic-pituitary activating system. Recent Progr. Hormone Res. 38:22, 1957.

3. ANTUNES-RODRIGUES, J. - Contrôle hipotalâmico da ingestão seletiva de água e cloreto de sódio. Tese de doutoramento, Fac. Medicina de Ribeirão Prèto, 1962.

4. ANTUNES-RODRIGUES, J. - Estudos sôbre a influência do hipotálamo na ingestão de sódio. Tese de docência, Fac. Medicina de Ribeirão Prêto, 1968.

5. ChagAs, C. - Processos patogênicos da tripanosomiase americana. Mem. Inst. O. Cruz 8:5, 1916.

6. CHAGAS, C. - Tripanosomiase americana. Forma aguda da moléstia. Mem. Inst. O. Cruz 8:37, 1916.

7. CROWELL, B. C. - The acute form of american trypanosomiasis. Notes on its pathology, with autopsy report and observations on trypanosomiasis in animals. Am. J. trop. Med. 3:425, 1923.

8. GROOT, J. - The rat forebrain in stereotaxic coordinates. Trans. Royal Neth. Acad. Sci. 52:11, 1959.

9. HESS, W. R. - Diencephalon. Autonomic and Extrapiramidal Functions. Grune \& Stratton, New York, 1954.

10. JARDIM, E. - Sudorese em pacientes com a moléstia de Chagas crônica. Arq. Neuro-Psiquiat. (São Paulo) 25:214, 1957.

11. KobERLE, F. - Patogenia da moléstia de Chagas. Estudo dos órgãos musculares ôcos. Rev. Goiana Med. 3:155, 1957.

12. KOBERLE, F. \& ALCANTARA, F. G. - Mecanismo da destruição neuronal do sistema nervoso na moléstia de Chagas. Hospital 57:173, 1960.

13. Koberle, F. - Patologia da moléstia de Chagas. Medicina CARL, Centro Acadêmico Rocha Lima da FMRP 1:73, 1962.

14. KOBERLE, F. - Aspectos neurológicos da moléstia de Chagas. Arq. NeuroPsiquiat. (São Paulo) 25:159, 1967.

15. LOMONACO, D. A. - Estudo da função tireoidiana na forma crônica da moléstia de Chagas. Tese de Docēncia, Faculdade de Medicina de Ribeirão Prêto, 1962. 
16. PRATES-CAMPOS, J. C. - Radioautographic study of the protein synthesis in the Purkinje cells at the acute phase of the experimental trypanosomiasis cruzi in rats. Rev. Inst. Med. trop. São Paulo 11:25, 1969.

17. REIS, L. C. F. - Estudo sôbre anormalidades observadas em curvas glicêmicas na moléstia de Chagas. Tese de doutoramento, Faculdade de Medicina de Ribeirão Prêto, 1963.

18. TORRES, C. M. - Sôbre a anatomia patológica da moléstia de Chagas. Mem. Inst. O. Cruz 36:391, 1941.

19. VIEIRA, C. B.; MAZZONCINI, M. \& LOMONACO D. A. - Variações da potassemia na forma crônica da moléstia de Chagas. Rev. paul. Med. 66:239, 1965.

20. WHITE, C. - The use of ranks in a test of significance for comparing two treatments. Biometrics 8:33, 1952.

Departamento de Neuropsiquiatria e Psicologia Médica - Faculdade de Medicina de Ribeirão Prêto da Universidade de São Paulo - Ribeirão Prêto, SP - Brasil. 